\title{
0 estudo dos efeitos não intencionais da açăo intencional na teoria sociológica
}

SILVIO SALEJ HIGGINS"

\section{Resumo}

No século 18, os ilustrados escoceses identificaram o paradoxo que haveriam de enfrentar depois as ciências sociais: a história é feita pelos seres humanos, mas não obedece a um plano humano. Neste artigo, reconstruímos a colocação deste problema central na tradição da teoria sociológica. Partimos da análise de Adam Smith, em sua tentativa de construir uma ciência social da produção riqueza. Logo nos ocupamos das primeiras colocações de Robert K. Merton no domínio da teoria sociológica. Passamos revista à forma como Raymond Boudon analisa o problema do ponto de vista do individualismo metodológico e ao modo como Anthony Giddens incorpora este paradoxo na explicação da reprodução social. Em uma avaliação preliminar, apontamos as limitações do funcionalismo mertoniano, na hora de explicar os efeitos não intencionais da ação intencional, mas, ao mesmo tempo, ressaltamos que o individualismo metodológico não fornece um conceito alternativo de causalidade. No final, tornamos explícito o debate ideológico que desata este paradoxo entre sociologias estruturalistas e reducionistas.

Palavras-chave: Efeitos combinatórios. Causalidade funcional. Dilemas sociais.

* Professor Adjunto do Departamento de Sociologia e Antropologia da UFMG e Coordenador da Pós-Graduação em Sociologia da UFMG. E-mail: sisahi@yahoo.com 


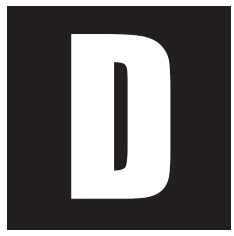

iz o provérbio popular que o inferno está cheio de almas com boas intenções. De forma mais sofisticada, Karl Popper (1980) havia apontado para o risco que representava a hibris ${ }^{1}$ daqueles que, ao tentar realizar o céu na terra, eram seduzidos a transformar a terra em um inferno. Podemos invocar uma linguagem religiosa para expressar este drama do coração humano:

Não faço o bem que queria, mas o mal que não quero. Ora, se faço o que não quero, já não sou eu que faço, mas sim o pecado que em mim habita. Encontro, pois, em mim esta lei: quando quero fazer o bem, o que se me depara é o mal - Rom 7, 19-21. (Bíblia, 1999).

De ordinário, ninguém confessa que entre suas intenções está o fazer mal aos outros, mas de fato sempre existem aquelas consequências das ações individuais que os economistas chamam de externalidades. Os efeitos não intencionais da ação humana, ou efeitos não antecipados da ação intencional (Merton, 1936), têm sido um tema enfrentado com mais frequência entre os economistas do que entre os sociólogos. Porém, hoje, como nunca, resulta ser um problema crucial para a pesquisa empírica e para a teoria social. Empregando diversas denominações, sociólogos da atualidade coincidem na ideia de que os efeitos não intencionais estão no centro dos problemas do mundo global: assistimos às consequências involuntárias da modernidade (Giddens, 1991), ou as sociedades industrializadas de hoje são caracterizadas pelo risco de não poder controlar os efeitos colaterais da tecnologia (Beck, 1992).

Neste trabalho, vamos reconstruir a colocação sociológica desse problema. Partiremos dos primórdios da ciência social moderna de Adam Smith (1984 [1776], 2002 [1759]), logo examinaremos o artigo pioneiro

1 Desmesura. 
de Robert K. Merton (1936), The unanticipated consequences of purposive social action, e as formulações teóricas de Anthony Giddens (1989) e Raymond Boudon (1977). No final, apresentamos, por uma parte, uma sinopse das críticas que recebeu a tentativa funcionalista de superar o estágio pré-científico nas explicações do problema dos efeitos de composição da ação social intencional, e, por outra, explicitamos o debate ideológico-político que desata este problema-limite das ciências sociais.

\section{Formulação do problema na economia política clássica}

No século 18, a ilustração escocesa identifica o paradoxo que haverão de enfrentar depois as ciências sociais: a história é feita pelos seres humanos, porém não obedece a um plano humano (Ferguson, apud. Elster, 1994). No contexto da eclosão da sociedade mercantil, levanta-se o debate em torno da virtude cívica e da coesão social ameaçadas pelo espírito do lucro individual. Para responder a esse problema, Adam Smith assume como pressuposto de sua economia política uma teologia natural de corte estoico. Deste ponto de vista, a providência divina, sob a metáfora da chamada "mão invisível", coordena as intenções egocêntricas dos atores econômicos. De forma semelhante, ainda que sem a sofisticação teórica de Smith, Bernard de Mandeville, provocador político amplamente conhecido na Europa, plasma sua apologia do mundo mercantil no célebre aforismo: "vícios privados, virtudes públicas" (Mandeville, 1996 [1714]). Essa era a moral de seu popular panfleto a fábula das abelhas. Tal microssociedade, a colmeia, colapsa quando um predicador introduz o amor ao próximo.

Para entender melhor como se postula a sintonia das ações individuais, no contexto da discussão moral da ilustração escocesa, precisamos identificar as coordenadas básicas do sistema moral de Adam Smith. Isto é, devemos lembrar que sua economia política - A Riqueza das Nações 
(1984, [1776]) é um tratado particular no conjunto de sua filosofia prática tal e como é desenvolvida na Teoria dos Sentimentos Morais (2002, [1759]).

Por uma parte, Smith analisa o ato moral, e, por outra, os mecanismos pelos quais é possível compreender e avaliar esse mesmo ato (Gutiérrez, 1998). No ato moral, podemos distinguir: a intenção ou motivos do ator, o ato em si mesmo, e os efeitos da ação sobre um paciente ou objeto. Por sua vez, os juízos morais são possíveis a partir da situação de um ator e um espectador, na qual se podem elucidar os elementos da ação moral no que se refere às motivações do ator, às afecções do espectador e à situação-limite de o ator e o espectador serem a mesma pessoa. A pergunta de partida do analista moral será a de como podemos aproximar-nos das intenções morais dos atores e dos sentimentos dos afetados, pois do conhecimento dos atos morais dependerão as considerações sobre seu mérito e sua justiça.

Sendo consequente com a teoria empirista do conhecimento, Smith considera que a imaginação é o único caminho possível para ter uma experiência sensitiva das paixões alheias, isto é, das motivações dos atos, dos atos mesmos e de suas consequências. Pois a partir da simples observação ou das declarações que as pessoas fazem sobre suas motivações, sempre ficamos por fora do que impulsiona a ação humana, isto é, das afecções sensíveis. Só através da imaginação estabelecemos a ponte com os sentimentos alheios. Deixemos que seja Smith quem o explique:

(...) nossos sentidos jamais poderão informar-nos sobre o que ele sofre. Nunca nos levam além de nossa própria pessoa, e só por meio da imaginação é possível para nós concebermos quais sejam suas sensações. Essa faculdade também não pode nos auxiliar nesse sentido de outro modo que não seja representando-nos as próprias sensações como se nos encontráramos em seu lugar. Nossa imaginação só copia as impressões de nossos próprios sentidos, não as alheias. Por meio da imaginação nos pomos no lugar do outro, concebemos estar sofrendo os mesmos tormentos, entramos, como se diz, em seu corpo, e, em certa medida, nos convertemos 
numa mesma pessoa, dali nos formamos uma idéia de suas sensações, e ainda sentimos, algo que, se bem em menor grau, não é totalmente semelhante a elas (Smith, 1759 apud Gutiérrez, 1998, p. 35).

Este exercício da imaginação é considerado o patamar da interação humana. Porém, não se trata de um ato de benevolência inspirado em considerações racionais, mas uma ação para constatar as afeições naturais, isto é, as espontâneas e comuns a todos os seres humanos. A imaginação é um vínculo de sensações e não de pessoas. O que importa para nosso propósito é mostrar como, no modelo teórico de Smith,a interação moral é, no nível mais elementar, um assunto impessoal. Este naturalismo permitirá a Smith sustentar a existência de duas ordens morais, uma natural, a que, segundo suas convicções deístas, é a marca da providência divina, e uma vigente que depende das circunstâncias históricas e culturais, mas que em últimas é uma encarnação imperfeita e, em muitos casos, torta, da primeira (Gutiérrez, 1998).

Depois de um percurso cheio de distinções sutis, no qual demonstra os limites do ato imaginário pelo qual nos colocamos no lugar do outro, e as dificuldades que encerra a avaliação de mérito ou demérito sobre os atos alheios, Smith considera plausível, ainda que empiricamente impossível, atingir a perspectiva de um observador imparcial. Só desde o tribunal da absoluta perfeição é que podemos superar as inconsistências da moral vigente (legalidade institucional) e também ser espectadores de nós mesmos. Em todas as situações que nos interrogamos pelo sentido do dever, além da censura e da aprovação social, ou no limite de querer agir como juízes da humanidade, devemos apelar ao tribunal superior inscrito em cada um dos seres humanos ${ }^{2}$. A sutileza de Smith radica em

2 Note-se a semelhança com a filosofia moral de Kant. À primeira vista, fica a impressão de que a pré-sintonia natural dos sentimentos morais de Smith, válida para todos os seres humanos sem importar o tempo e o lugar, coincide tanto com a pré-sintonia do sujeito lógico-transcendental 
naturalizar a perfeição, e por essa via introduzir uma sorte de harmonia preestabelecida sobre a qual estariam sustentadas as ações dos seres humanos. Nesse sentido, entende-se por que Smith pensa que, strictu sensu, à finitude humana só lhe compete avaliar as motivações da ação e seus efeitos intencionais. Assim, o campo da intencionalidade está reservado à teoria moral, enquanto o campo dos efeitos não intencionais da ação humana está reservado à ciência social objetiva, no sentido empirista que se Ihe atribui à objetividade. Dessa forma, estamos em condições de entender por que na Economia Política não são relevantes as avaliações morais sobre as intenções dos agentes econômicos.

Em síntese, o que nos interessa destacar aqui é o seguinte paralelo: assim como a ciência natural descobre a coesão e recorrência dos fenômenos observáveis, a ciência social se encarrega de estudar a coesão e recorrência dos efeitos não intencionais da ação humana. À continuação oferecemos um gráfico que reúne os diferentes níveis de coesão dos sentimentos morais na filosofia prática de Adam Smith.

de Kant (razão teórica) como com a pré-sintonia moral dos seres razoáveis no reino dos fins em si (razão prática). Porém, não há tal identidade. O idealismo transcendental kantiano não admite a perspectiva empirista de Smith, pois na óptica de Kant não há lugar para que a sensibilidade dite critérios de aprovação ou desaprovação moral. O kantismo é um sistema de pensamento desgarrado pela dualidade entre os interesses da subjetividade empírica e intenção pura da subjetividade prática. Este comentário é pertinente em razão de que a moral kantiana do dever instaura a restrição moral da pessoa com fim em si mesmo. Tal limite se ergue como um cilício constante frente aos fundamentos hedonistas da economia política clássica. 
Gráfico 1. Teoria dos sentimentos morais (Smith, 2002[1759])

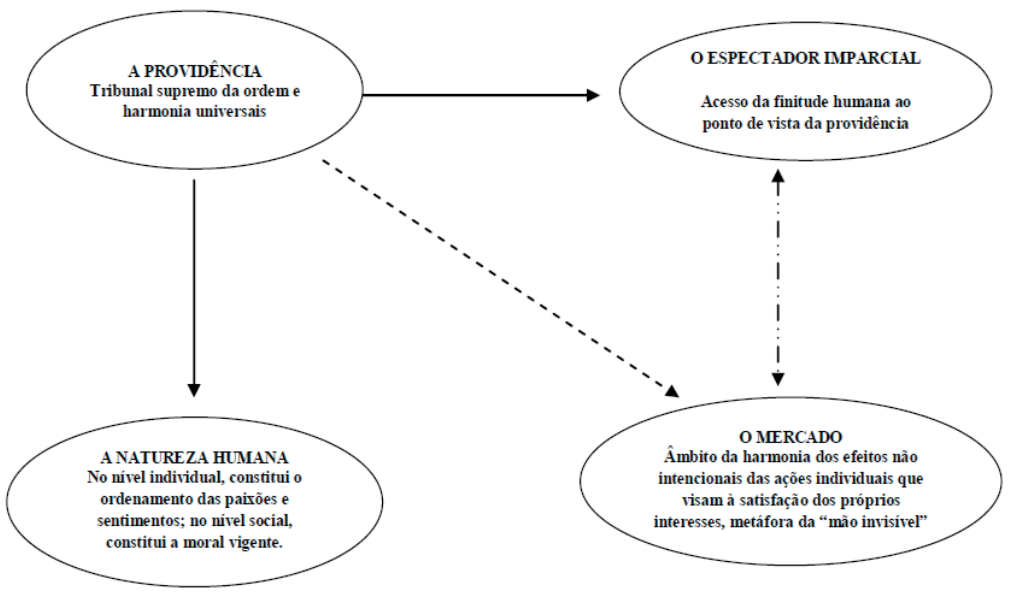

Fonte: elaboração própria

\section{Indicações para interpretar o gráfico}

Deve levar-se em conta que a providência é o postulado da suprema harmonia universal. Tal harmonia, incompreensível para o entendimento finito do ser humano, imprime sua marca na natureza humana, na consciência moral e no mercado. As diversas linhas distinguem diversas ordens causais:

$\longrightarrow$ Ordem causal das ações intencionais.

-.-.--> Ordem causal das consequências não intencionais

$\longleftrightarrow \rightarrow$ Analogia estrutural: o mercado opera na vida social como instância de imparcialidade, análoga ao ponto de vista do espectador imparcial próprio da providência, neste sentido, o mercado é o tribunal supremo da justiça social. 


\section{As colocações pioneiras de Robert K. Merton}

Em seu célebre artigo de 1936, The unanticipated consequences of purposive action, Merton reconhece que o problema dos efeitos não antecipados da ação intencional é um assunto de longa data no pensamento social. Foi apontado na renascença por Maquiavel e Vico. Como vimos antes, também foi assunto recorrente na teoria social moderna desde Adam Smith até Max Weber, passando por Marx e Engels, Wundt e Pareto. Porém, segundo Merton, tanto a diversidade de campos analíticos, na qual é apontado o problema - na teologia, na historiografia, nos estudos sobre a tecnologia, etc. - quanto a atribuição da intervenção do destino e da providência impedem um tratamento científico que seja verdadeiramente sistemático.

Merton (1936) começa por evitar mal-entendidos. Para isso, levanta várias distinções:

- Efeitos não antecipados, ou imprevistos, não se identificam com efeitos indesejáveis para o agente. Mas, efeitos antecipados são intrinsecamente desejados pelo agente. Ao mesmo tempo, reconhece que a identificação de um resultado está sujeita à dificuldade que envolve a ação recíproca entre as circunstâncias e a ação.

- Merton distingue entre as consequências para o agente e para os outros, estando estas últimas mediadas pela cultura, pela estrutura social e pela civilização.

- Sucesso ou insucesso, de uma ação intencional, é diferente de racionalidade ou irracionalidade. Podemos agir racionalmente dentro de um espaço de possibilidades limitado, selecionando o meio adequado, porém, sem atingir o objetivo almejado. Ao contrário, podemos atingir um fim determinado através de meios irracionais, como é o caso de seguir uma premonição. 
- Há dois tipos de ações propositivas: as ações formalmente organizadas, mediante arranjos de coordenação (estatutos, incentivos, sanções negativas, etc.), e as ações não organizadas. Para Merton, do ponto de vista sociológico, são mais importantes as últimas. Isto é, podemos gerar efeitos sociais agregados, benéficos ou não, a partir de inúmeras ações individuais.

- Do ponto de vista metodológico, colocam-se dois problemas: por um lado, a imputação causal, como e em que medida determinadas consequências podem ser atribuídas a ações específicas, por outro, a dificuldade de atribuir intenções a uma ação, isto é, como podemos distinguir entre uma intenção verdadeira e uma justificativa ex-post-facto.

Em um segundo momento, e dado o estado dos conhecimentos atuais de um observador, Merton identifica três fatores que impedem a antecipação das consequências não esperadas:

- À diferença das ciências físicas em que há associações funcionais entre variáveis, nas ciências sociais, a falta de controle experimental conduz a associações estocásticas entre variáveis. Isto é, as consequências de um ato repetido não são constantes. A limitação no conhecimento de uma ação abre um amplo leque de resultados inesperados.

- O erro é fonte de consequências não esperadas. Entra em qualquer fase da ação intencional: no diagnóstico, na inferência da situação futura, na seleção do curso de ação e na execução da ação escolhida. Merton identifica dois mecanismos que induzem ao erro: 1) a falácia do hábito, pensar que as ações exitosas do passado continuarão a sê-lo e 2) a parcialidade, seja por esquecimento ou falta de sistematicidade, ou por obsessão patológica ou envolvimento afetivo. 
- A força imperativa e imediata do interesse faz com que o ator não leve em conta consequências ulteriores de seu próprio ato. Nesse ponto, Merton alerta para o risco de uma leitura apressada das análises de Max Weber. Agir de forma interessada não implica, necessariamente, um cálculo racional da situação. O interesse é fonte de viés emocional, e uma ação que é racional em relação com um valor básico do interesse pode ser irracional em relação com outros valores do indivíduo. De forma mais paradoxal ainda, uma ação interessada pode voltar-se contra si mesma, como no caso do ascetismo no qual a atividade produtiva e o declínio do consumo conduzem ao acúmulo de riqueza.

É necessário lembrar que Merton não desenvolve, nesse artigo de 1936, o conceito de causalidade funcional. Só fica insinuado. O conceito de função social é a resposta mertoniana ao como acontece a agregação social de efeitos não previstos pelas ações intencionais dos indivíduos. A distinção, elaborada por Merton, entre função manifesta e função latente tem sido objeto de acirradas críticas de epistemólogos das ciências sociais (Helm, 1971, Elster, 1994). Essas serão apresentadas no conjunto da avaliação crítica deste artigo.

\section{Os trabalhos de Raymond Boudon ${ }^{3}$}

Na coletânea Effets Pervers et Ordre Social (1977), o sociólogo francês Raymond Boudon sublinha o fato de que os efeitos colaterais são familiares aos economistas mas não aos sociólogos. Começa ilustrando o assunto com um caso tipo da atividade econômica:

Em período de inflação, eu tenho interesse em comprar hoje um produto que somente utilizarei o no próximo mês dado

3 A tradução das citações é nossa. 
que estou quase seguro que subirá de preço. Agindo assim, eu contribuo à perpetuação da inflação. Naturalmente meu comportamento só possui uma influência infinitesimal nesse nível, mas a lógica da situação faz com que muitas pessoas se comportem como eu mesmo o faço. A adição destas influências individuais infinitesimais engendra, pois, um efeito social (Boudon,1977, p. 5)

Boudon destaca o artigo de Merton (1936), acima referenciado, como um texto seminal, porém raro, dentro do campo da sociologia. "Os efeitos perversos são frequentes na vida social, porém são raros na análise sociológica moderna" (Boudon, 1977, p. 5). Para este sociólogo francês, o modelo analítico dos efeitos perversos pode ser delimitado a partir de uma definição do fenômeno e de uma combinatória sistemática de critérios: "trata-se de efeitos individuais ou coletivos que resultam da justaposição de comportamentos individuais sem que estes efeitos estejam entre os objetivos visados pelos autores" (ibid.).

O ponto-chave da definição radica em entender que os efeitos não intencionais, bons ou perversos, não são visados nos objetivos dos atores sociais. Por exemplo, um incremento pela demanda escolar gerará um incremento da produtividade econômica. Esse efeito positivo não é um objetivo desejado pela ação dos indivíduos caso a caso, como também não é desejada a elevação dos custos educativos (Boudon, 1977).

Para Boudon, a onipresença dos efeitos perversos na vida social desafia os modelos habituais com que a teoria sociológica contemporânea aspira a explicar a ação social. A ênfase nos efeitos da ação foca a atenção no agente e suas intenções, entendidos como causas e não como simples efeitos das forças socais. Esse deslocamento da atenção é reflexo das lutas ideológicas do campo sociológico na década dos anos 70 do século 20. Avaliamos que, em um contexto intelectual como a França dos anos 70, Boudon toma partido por uma versão matizada do individualismo metodológico e contra o estruturalismo que dominava as ciências sociais. Sua consigna pode ser resumida 
nos seguintes termos: "O sociólogo não pode ignorar o lugar da liberdade sem ficar exposto a sérios problemas" (Boudon,1997, p.6).

A partir dos critérios utilizados por Boudon, podemos estabelecer o seguinte tópico sobre os efeitos não intencionais da ação humana:

Gráfico 2. Ação social e efeitos perversos (Boudon, 1977)
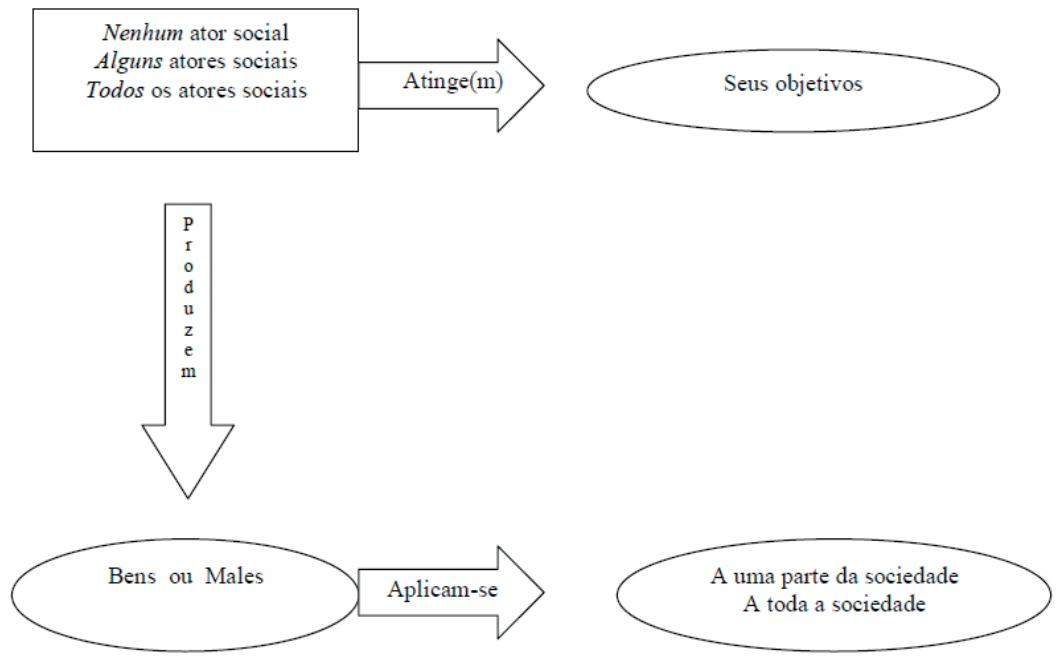

Fonte: elaboração própria a partir de Boudon (1977)

No ensaio Déterminismes Sociaux et Liberté Individuelle, que faz parte da coletânea aqui resenhada, Boudon (1977) explicita as convicções sob as quais interpreta os efeitos colaterais da ação humana. Para ele, os paradigmas teóricos da sociologia podem ser classificados em duas grandes famílias: os paradigmas deterministas e os paradigmas interacionistas. No primeiro, os atos humanos são entendidos em termos de comportamento, isto é, de respostas a estímulos. Nessa perspectiva, os fenômenos são explicados a partir de causas eficientes, como o resultado exclusivo 
de fatores temporalmente anteriores ao comportamento em questão. No segundo, os atos humanos são entendidos como comportamentos orientados por fines. Nesse caso, pode-se falar de ação em estrito sentido e de causalidade em sentido teleológico.

O ponto-chave, na perspectiva de Boudon, radica na assimetria das duas famílias de modelos. Isso significa que só os modelos interacionistas fundamentam de forma adequada a análise sociológica.

O sociólogo não pode ignorar estas diferentes manifestações da liberdade individual. O aparecimento de comportamentos "desviantes", de efeitos de composição, ou a mudança social é, na maioria dos casos, ininteligível se não há um esforço para analisar o lugar que ocupa a liberdade em suas diferentes manifestações (Boudon, 1977, p. 246).

Levar em conta a liberdade supõe distinguir dois subconjuntos de paradigmas de tipo interacionista, cuja nomeação Boudon toma emprestada da filosofia política contratualista do século 18. Assim, há ações que não supõem consulta nem aprovação de outros atores sociais, estas se enquadram no modelo de estado de natureza. A este corresponde a esfera privada com as liberdades individuais e os direitos de propriedade. Outras ações, que supõem acordos entre atores, se enquadram no modelo de estado de contrato. Aqui está excluída a esfera privada, e as ações se enquadram em roles sociais preestabelecidos regidos por sistemas de obrigações (normas e sanções).

Em síntese, os efeitos não intencionais da ação intencional, chamados por Boudon de "efeitos de composição", resultam relevantes para o estudo sociológico se:

- São lidos no interior de um paradigma interacionista, em que somente os atores sociais que agem intencionalmente geram efeitos de composição ao estilo do dilema do prisioneiro, pois não há dilemas sociais sem as noções de antecipação, escolha e preferências. 
- Se é adotada uma estratégia de simplificação ou redução metodológica da complexidade social, esta e é uma das premissas básicas do chamado individualismo metodológico.

- Se a ação individual intencional é considerada como o fundamento metodológico da análise sociológica.

As teses de Boudon demandam algumas precisões. Em primeiro lugar, quando afirma que os efeitos de composição só fazem sentido dentro de paradigmas interacionistas e sob a ótica do dilema do prisioneiro, omite uma distinção básica da teoria dos jogos. A saber, em teoria dos jogos se diferencia entre dilemas de duas pessoas e dilemas de $n$ pessoas (Kollo$c k, 1998)$. Dentro dos primeiros, o famoso dilema do prisioneiro ilustra o teorema de Nash. Isto é, jogos finitos de decisões interdependentes têm ao menos uma situação de equilíbrio. Isso significa que cada ator não está disposto a mudar sua estratégia, dada a estratégia do outro. Se aplicamos modelos de duas pessoas a situações coletivas, corremos o risco de fazer a extrapolação típica da filosofia utilitarista, a de pensar o saldo líquido de bem-estar social a partir de um modelo de escolha individual.

Os dilemas de $n$ pessoas correspondem às situações nas quais a lógica do cálculo de utilidade conduz à ruína coletiva. Existem duas situações tipo: a tragédia dos commons e a tragédia dos bens públicos. A primeira foi formulada no contexto da problemática ambiental para designar que o livre acesso aos recursos naturais de uso comum conduz ao esgotamento dos mesmos. Trata-se de uma situação em que ninguém é excluído e em que o consumo de cada usuário é uma subtração ao consumo dos outros. A segunda tipifica o comportamento com relação ao usufruto de um bem público (um parque, uma estrada). Como na anterior, ninguém é excluído de sua produção, mas não há subtração ao consumo dos outros.

Boudon não aplica sua própria distinção entre modelos interacionistas de estado de natureza e modelos de estado de contrato. Poderia ter 
afirmado que a solução dos dilemas de duas pessoas corresponde a um equilíbrio estratégico na esfera dos assuntos privados, mas que a solução dos dilemas coletivos supõe a complexa mediação das normas e os valores coletivos. Isso suscita a pergunta pela solução intencional de efeitos perversos não intencionais.

\section{A Teoria da Estruturação de Anthony Giddens}

Não poderíamos compreender a perspectiva de Giddens, em relação aos efeitos não intencionais da ação humana, sem antes fixar a orientação geral de seu manifesto teórico para a sociologia, tal e como aparece na Teoria da Estruturação (1989).

Nessa obra, Giddens toma partido pela que ele denomina como acepção fraca da teoria no campo sociológico. De forma análoga à postura mertoniana sobre as teorias de alcance médio, Giddens sustenta que a descoberta de generalizações, ou leis, não é tarefa fundamental da teoria social. Pelo contrário, os teóricos sociais deveriam ocupar-se de:

- reelaborar concepções do ser humano;

- reelaborar concepções do fazer humano;

- repensar a reprodução social;

- repensar a transformação social.

$\mathrm{Na}$ intenção de Giddens, a reprodução e a transformação constituem o núcleo da teoria social. Assim, o trabalho-chave do sociólogo consiste em desvendar como as limitações da "presença", das interações aqui e agora, são transcendidas pela extensão das relações sociais através do tempo-espaço. Em consequência, só há estrutura social se os comportamentos se reproduzem (alongam) no tempo e no espaço: 
A oposição entre micro e macro é melhor re-conceituada no que se refere ao modo como a interação em contextos de co-presença está estruturalmente implicada em sistemas de ampla distinção de Tempo/Espaço, ao modo como tais sistemas abrangem grandes setores espaço-temporais, de integração social e de sistemas (Giddens, 1989,p. XXI).

Essa ênfase de Giddens, no que ele chama de ontologia do tempo-espaço, é em nosso entender um ponto inovador de sua teoria da estruturação. Para ele, tal teoria deverá aportar uma melhor compreensão da natureza humana e do self atuante, uma maior clareza das relações do self com as instituições e servirá para elucidar as conotações práticas da análise social. Para tal propósito, não é gratuito que Giddens use o substantivo inglês self para se referir ao que de forma habitual chamamos de subjetividade. O self sublinha o agir reflexivo para distingui-lo do agir intencional. De acordo com sua análise, a reflexividade designa a monitoração do fluxo da vida social, o que implica um processo contínuo que permite reconhecer a estabilidade e permanência das práticas sociais. Em tal sentido, o self é chave para a reprodução e a ordenação da vida social.

É na análise aprofundada do self em que Giddens identifica a relevância sociológica dos efeitos não intencionais da ação humana. Pergunta-se: só há agência quando há intencionalidade? Não, responde ele. A agência se refere à capacidade de fazer das pessoas e não às suas intenções. Isto é, ainda que não as quisermos, somos autores de muitas coisas que fazemos. Desta forma, a agência é o conjunto que incorpora o pré-intencional, o intencional e as consequências não intencionais. As relações entre reflexividade, intencionalidade e consequências não intencionais podem ser resumidas com a ajuda do seguinte gráfico: 
Gráfico 3. O Self - componentes do agir humano (Giddens, 1989)

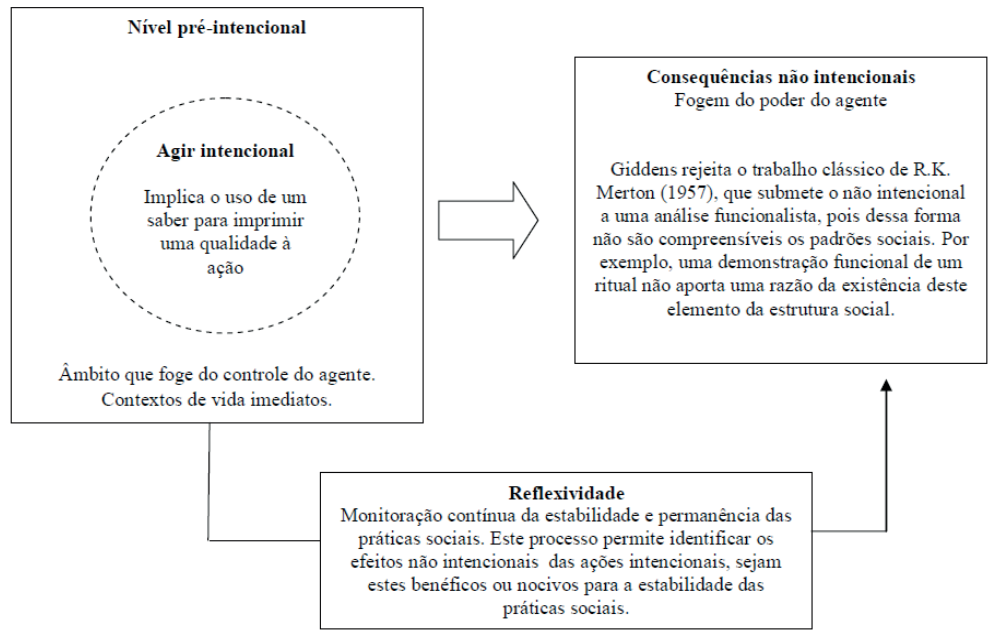

Fonte: elaboração própria a partir de Giddens (1989)

A análise anterior é crucial, porque permite a Giddens afirmar que as circunstâncias de coerção social, nas quais os indivíduos não têm escoIha, não podem ser equiparadas com a dissolução da ação como tal. Isto é, segundo ele, o objetivismo equiparou coerções sociais com forças de natureza, como se "não ter escolha" fosse equivalente a ser irresistível e incompreensivelmente impelido por pressões mecânicas. Pelo contrário, para Giddens o poder de agir significa tanto a capacidade de intervir no mundo ou de abster-se como também a mobilização de tendências que estão embutidas nas instituições.

Em resumo, os efeitos colaterais, na análise do ator social feita por Giddens, são relevantes para entender a reprodução dos sistemas sociais como um resultado não intencional do agir intencional dos seres huma- 
nos. Esse processo acontece de forma rotineira no tempo e no espaço das relações interpessoais. À diferença de Durkheim, quem nas Formas Elementares da Vida Religiosa (1912 [2000]) dá destaque ao tempo e ao espaço sagrado como a ocasião em que se faz mais intensa a fusão da energia social, Giddens enfatiza a condição social do tempo e do espaço rotineiro. Porém, cabe perguntar qual é a margem que Giddens estaria disposto a aceitar, para o agir intencional, quando se trata de mudar as que ele chama de "propriedades estruturais dos sistemas sociais".

\section{Avaliação crítica e análise comparativa}

O problema que enfrentam as posturas teóricas, antes referenciadas, exige ser examinado em dois níveis: metodológico e onto-prático ${ }^{4}$. No primeiro, é crucial explicitar o tipo de explicação causal que pode invocar a teoria sociológica e no segundo se exige apontar o debate político que permeia a construção de teorias sociais.

No nível metodológico, deve-se salientar que o esforço pioneiro de Robert K. Merton avançou na direção de superar as explicações pré-científicas, incluída a metáfora da mão invisível de Adam Smith, em relação ao problema dos efeitos não antecipados da ação social intencional. Em trabalhos posteriores ao artigo de 1936, Merton formula o conceito de causalidade funcional e distingue entre funções sociais manifestas e latentes. Sem entrar nos detalhes do paradigma da teoria de sistemas que dominou a sociologia norte-americana da primeira metade do século 20, lembramos que o funcionalismo visa explicar a persistência de certos elementos da vida social ou, em termos de Talcott Parsons, o problema da ordem social.

4 O termo 'onto-prático' é um neologismo com o qual designamos a dimensão metafísica, não suscetível de falsações empíricas, da vida social. Um dos redutos da metafísica, após o desencantamento do mundo pela ciência experimental, continua a ser a axiologia política. A política é a arena prática na qual se trava a luta de valores sociais. 
Se, do ponto de vista sistêmico, o funcional é aquilo que aporta estabilidade e ordem ao sistema social, Merton coloca a distinção entre comportamentos sociais que cumprem funções manifestas e aqueles que cumprem funções latentes. Define as funções manifestas como "aquelas consequências objetivas que contribuem ao ajuste e adaptação do sistema as quais são pretendidas e reconhecidas pelos participantes no sistema" (Merton, 1957, p.51). De forma contrastante, define as funções latentes como "aquelas que não são nem pretendidas nem reconhecidas [pelos participantes no sistemal" (Merton, 1957,p.51). A função latente corresponde ao famoso ditado de Karl Marx, apontado também pelos ilustrados escoceses, de que a história acontece às costas dos atores sociais (Marx, 1946).

Segundo o exemplo analisado por Merton, uma tribo indígena que executa uma dança para atrair a chuva pode dar cumprimento, mediante seu ritual, a duas funções sociais não coincidentes (Merton, 1957). De acordo com as definições supracitadas, a função manifesta do ritual visa a um efeito empírico além do sistema social, fazer chover, enquanto que a função latente consiste na manutenção e/ou incremento da coesão social. Ainda que não chova, os membros da tribo, sem pretendê-lo e talvez sem reconhecê-lo, podem sair, do ritual, mais confiantes na disposição positiva de todos para enfrentar um problema comum.

$\mathrm{Na}$ tradição sociológica, o funcionalismo tem sido alvo de acirradas críticas pelo que é considerado seu caráter pseudocientífico. Em particular, os paradigmas sociológicos reducionistas, na linha do individualismo metodológico professado por Boudon, consideram que a explicação funcional é um recurso típico de sociologias estruturalistas, as quais enfatizam o agir compulsório dos indivíduos pela força das limitações materiais, as normas e os valores socais. Mas, a rejeição mais importante aponta ao caráter tautológico e ex-post-facto do conceito de função latente (Elster, 1989, 1994). Do ponto de vista da construção da evidência empírica, o 
sociólogo sempre deverá esperar o resultado latente para verificar se um determinado elemento do sistema social, um ritual, por exemplo, traz coesão e estabilidade ao próprio sistema. Tal avaliação retrospectiva (expost-facto) conduz a identificar funções latentes ali onde há ordem e coesão social, seria como dizer que "algo é socialmente funcional porque funciona bem", o que constitui um truísmo que não aporta nada novo ao conhecimento sociológico. Além disso, o conceito de função latente não permite entender por que e como um determinado elemento do sistema social é seguido regularmente pelos efeitos benéficos que lhe são atribuídos. Em outras palavras, a explicação funcional não identifica o mais importante do ponto de vista científico: o mecanismo causal ou como se dá a associação entre dois fatores sociais (Elster,1994).

Outra inconsistência da explicação funcional, apontada com frequência, reside na incapacidade de fornecer dados sobre a gênese de determinadas instituições. Parsons (1990), por exemplo, identifica a função do matrimônio dentro do sistema social, enquadrar as trocas matrimoniais na busca de valores últimos, mas não explica, por exemplo, por que vigora o matrimônio monogâmico e não o matrimônio poligâmico em um determinado sistema social (Coleman, 1990).

Ate aqui, é necessário salientar que as críticas ao funcionalismo não preenchem ainda o vazio científico sobre o tipo de causalidade adequado para explicar os efeitos de composição da ação social intencional. Elster, por exemplo, se limita a constatar que o problema da ordem social, ou o "cimento da sociedade", como ele diz, visto na óptica do individualismo metodológico, coloca-se em duas dimensões: no nível da previsibilidade da ação social e no nível da coordenação que garante a cooperação entre os atores sociais (Elster, 1989b). O axioma básico de que os indivíduos agem buscando sua própria utilidade torna previsíveis certos equilíbrios estratégicos da interação social. Nesse nível, trabalham os modelos mate- 
máticos da teoria de jogos, visando definir situações-tipo de barganha, ao estilo do dilema do prisioneiro, para identificar estratégias dominantes e equilíbrios na antecipação racional dos atores. Mas a teoria de jogos não tem como foco principal os mecanismos de coordenação que garantem resultados cooperativos em jogos de $n$ pessoas. Sobre esse ponto, Elster identifica várias situações-tipo nas quais estão em questão efeitos de composição cooperativos: os dilemas sociais (dilemas de $n$ pessoas), a interação mediada por normas sociais e diversas formas de interação contratual.

Em nossa avaliação, do ponto de vista sociológico, o assunto-chave na agenda da pesquisa social consiste em tornar visíveis os mecanismos pelos quais opera a mão invisível da prosperidade. Ali onde os economistas somente avaliam a agregação do cálculo de utilidade individual, os sociólogos estão chamados a explicitar os incentivos coletivos (valores sociais) e os mecanismos de controle social (normas sociais) que limitam o oportunismo generalizado.

No nível onto-prático, anteriormente anunciado, empregamos como fio condutor a questão crucial que levantou Popper para o conhecimento histórico: Como submeter o conhecimento do mundo social ao critério de demarcação científica? Como evitar cair nas filosofias da história de Hegel e de Marx, as quais não são outra coisa do que profecias autoinduzidas?

O assunto não é de pouca monta, em razão de que constitui o alvo do ataque liberal ao pensamento utópico: aqueles que pretendem construir o céu na terra terminam construindo o inferno (Popper, 1980). Esta denúncia de Popper permite fazer a ponte entre o critério de cientificidade e os efeitos não intencionais da ação humana. Isto é, nos leva a perguntar qual é o discurso científico que permite explicar os efeitos não intencionais do agir humano? A tarefa que Popper visualiza para as ciências sociais está no foco do presente trabalho: "Esta observação nos ofe- 
rece a ocasião de enunciar a tarefa principal das ciências sociais teóricas. Esta consiste em determinar as repercussões sociais não intencionais das ações humanas intencionais" (Popper, Conjectures and Refutations, apud. Boudon, 1977, p.5).

Em termos popperianos, o problema comum às posturas de Smith, Merton, Boudon e Giddens reside no desejo do céu que conduz ao inferno. Isso significa que afirmam a liberdade humana como princípio da ação e ao mesmo tempo declaram a finitude da racionalidade. Dessa forma, pressupõe-se uma desproporção ontológica no ser humano, entre a vontade de uma liberdade irrestrita e as limitações das potências intelectivas. Em palavras simples: indivíduos livres não são capazes de prever os efeitos agregados de seus atos. Entramos assim no terreno de uma discussão acirrada, própria da filosofia política que funda a modernidade.

Quando se fala de efeitos não intencionais da ação humana, aparecem enfrentadas as duas grandes ideologias políticas da modernidade, liberalismo e socialismo. Cada uma pressupõe que a vida social constitui uma totalidade. Já sabemos por Hegel que quando se fala de totalidade se diz de alguma forma uma síntese ou reconciliação de todas as contradições ${ }^{5}$. Mas os postulados da totalidade social, de liberais e socialistas, resultam conflitantes entre si. Em tal sentido, os sociólogos que postulam a liberdade individual, como Boudon, enquanto princípio explicativo, jogam o problema dos efeitos não intencionais contra as sociologias que eles consideram como deterministas, leia-se totalitaristas. Na perspectiva dos sociólogos liberais, a tentativa de construir estruturas sociais que consertem todos os problemas econômicos e políticos, via planejamento, como foi pretendido pelas revoluções de inspiração marxista, defronta-se com um grande efeito não intencional indesejável: a perda de liberdade

5 A ideia de totalidade constitui o horizonte utópico das ideologias políticas da modernidade. 
individual que destrói os incentivos da produtividade e da inovação econômica e política. Do ponto de vista do individualismo liberal, as instituições sociais não são o resultado de um planejamento total. Em sentido popperiano, ao pretender fazer instituições perfeitas, o céu na terra, terminam construindo o inferno. Constata-se assim que as estruturas sociais são resultado da ação humana, mas não obedecem a um plano humano.

Porém, o liberalismo político se declara contrário às visões totalizantes da sociedade sem ver a palha em seu próprio olho. Vimos como Adam Smith e Mandeville postulam, via convicções teológico-metafísicas da mão invisível, que a vida social constitui uma totalidade orgânica e que os vícios privados se tornam virtudes públicas no âmbito do mercado. No começo do século 20, a teoria geral do equilíbrio econômico de WalrasPareto substitui a metáfora da mão invisível sem substituir os pressupostos metafísicos que fazem acreditar em uma tendência espontânea dos fatores econômicos em busca de um ponto de otimalidade. Em sociólogos contemporâneos como Giddens, tais postulados metafísicos de uma providência divina não têm cabimento; o que se postula é uma ontologia do tempo-espaço, em termos da inércia cotidiana da vida prática, como chave de compreensão da reprodução das instituições.

Finalmente, devemos sublinhar que a insistência do individualismo metodológico, também poderíamos chamá-lo de liberalismo metodológico, na incerteza dos efeitos não intencionais do agir humano tem seus próprios efeitos colaterais. Isto é, leva a não problematizar as totalizações e os paradoxos dos próprios pensadores liberais: a mão invisível de Adam Smith, a racionalização do mundo como filosofia da história em Weber, a sociedade aberta de Popper que exclui aqueles que são definidos como seus inimigos. 


\title{
The study of unintentional effects of intentional action in the sociological theory
}

\begin{abstract}
In the $18^{\text {th }}$ century, Scottish scholars identified the paradox that social sciences would have to face later on: history is made by human beings, though it does not obey a human plan. In this article, we reconstruct the rank of this central problem in the tradition of the sociological theory. We start from the analysis of Adam Smith, in his attempt to build a social science of wealth production. Then we deal with the first theses of Robert K. Merton in the domain of the sociological theory. We examine the way in which Raymond Boudon analyzes the problem from the perspective of methodological individualism and the way that Anthony Giddens incorporates this paradox in his explanation of social reproduction. In a preliminary evaluation, we point out the limitations of Mertonian functionalism in explaining nonintentional effects of intentional action, although, at the same time, we emphasize that methodological individualism does not provide an alternative concept for causality. In the end, we lay out the ideological debate that unfastens this paradox between structuralist and reductionist sociologies.
\end{abstract}

Keywords: Combinatory effects. Functional causality. Social dilemmas.

\section{Referências}

BECK, Ulrich. The Reinvention of Politcs: Rethinking Modernity in the Global Social Order. Cambridge: Polity Press, 1992.

BIBLIA SAGRADA. São Paulo: Edição Claretiana, 1999.

BOUDON, Raymond. Effets Pervers et Ordre Social. Paris: Presses Universitaires de France, 1977.

COLEMAN, James S. Commentary to "Prolegomena to a theory of social institutions". In: PARSONS, Talcott. Prolegomena to a theory of social institutions. American Sociological Review, , Vol. 55, p. 313-345, June 1990.

DURKHEIM, Émile. As Formas Elementares da Vida Religiosa. São Paulo: Martins Fontes, 2000. 
ELSTER, Jon. Karl Marx. Une interprétation analytique. Paris : Presses Universitaires de France, 1989a.

. The cement of society. Cambridge : University Press, $1989 \mathrm{~b}$.

Dumará, 1994.

. Peças e Engrenagens das Ciências Sociais. Rio de Janeiro: Relume

FOUCAULT, Michel. Microfísica do Poder. Rio de Janeiro: Edições Graal Ltda., 1993.

GIDDENS, Anthony. A Constituição da Sociedade. São Paulo: Martins, Fontes, 1989.

. As Conseqüências da Modernidade. São Paulo: Editora Unesp, 1991.

GUTIÉRREZ, Germán. Ética y Economia en Adam Smith y Friedrich Hayek. San José de Costa Rica: DEI, 1998.

HINKELAMMERT, Franz. Frente a la cultura política de la postmodernidad: proyecto político y utopía. Revista Pasos, San José de Costa Rica: Departamento Ecuménico de Investigaciones (DEI), No 12, 1987.

MANDEVILLE, Bernard de. Uma investigação sobre a origem da virtude moral. In: CABRAL, Álvaro (Tradutor). Filosofia moral britânica, textos do século XVIII. Campinas: Editora da Unicamp, Vol I, 1996 [1714].

MARX, Karl. El Capital. México D.F.: Fondo de Cultura Económica, 1946.

MERTON, Robert K. The unanticipated consequences of purposive social action. American Sociological Review, I, p. 894-904, 1936. 1957.

. Social Theory and Social Structure. Illinois: Glencoe (revised edition),

PARSONS, Talcott. Prolegomena to a theory of social institutions. American Sociological Review, Vol. 55, p. 313-345, June 1990.

POPPER, Karl. A miséria do historicismo. São Paulo: Cultrix, 1980.

KOLLOCK, Peter. Social Dilemas: The Anatomy of Cooperation. Annual Review of Sociology, v. 24, p. $183-214,1998$.

SMITH, Adam. Investigação sobre a natureza e as causas da riqueza das nações. São Paulo: Víctor Civita, 1984 [1776].

. Teoria dos Sentimentos Morais. São Paulo: Martins Fontes, 2002 [1759].

Recebido em: 18/03/2011

Aceite final: 05/08/2011 